\title{
Prevalence of Metabolic Syndrome and its Component in Patients with Acute Coronary Syndrome.
}

\author{
Ajay Rajbhandari ${ }^{1}$, Dipendra Raj Pandeya ${ }^{2}$, Madur Dev Bhattarai ${ }^{3}$, Ravi Malla ${ }^{4}$, Arun Sharma ${ }^{1}$, \\ Dina Shrestha ${ }^{5}$, Pratik Chettry ${ }^{1}$. \\ ${ }^{1}$ Shree Birendra Hospital, Chauuni, Kathmandu; ${ }^{2}$ Nepalese Army Institute of Health Sciences, \\ Sanobharyang, Kathmandu; ${ }^{3}$ National Academic of Medical Sciences, Maha bhaudha, \\ Kathmandu; ${ }^{4}$ Shahid Ganga Lal National Heart Center, Kathmandu; ${ }^{5}$ Bir Hospital, Mahab- \\ haudha, Kathmandu.
}

\begin{abstract}
Introduction: The Metabolic syndrome is a cluster of risk factors associated with risk of coronary artery disease causing morbidity and mortality in both developing and developed countries. The aim of this paper was to evaluate the prevalence of Metabolic Syndrome and to evaluate its cardiovascular risk potential using the National Cholesterol Education Program's Adult Treatment Panel III Criteria.

Methods: It was a hospital based case control study carried out in Cardiac Care Unit in Bir Hospital and Shahid Ganga Lal Heart Center in Kathmandu, Nepal, from 16th July 2005 to 10th August 2006. Total 209 patients with Coronary Artery Disease (Acute Coronary Syndrome) were enrolled. Patients having coronary by-pass surgery in past, age less than 18 years and other co-morbid diseases were excluded. The cardiovascular risk factors that define the metabolic syndrome and their correlation with the cardiovascular risk were evaluated by descriptive and interferential statistical methods. All analysis was carried out using SPSS 19. A p value $<0.05$ was considered as significant.

Results: A total of 209 patients of coronary artery disease were studied with a mean age of $57.87 \pm 12.45$ years (range 27-88 years). Metabolic Syndrome was present in 120 (57.4\%) patients. Out of 120, male and female were $78(65.0 \%)$ and $42(35 \%)$ respectively. Significant difference $(p<0.05)$ between male with metabolic syndrome and female with metabolic syndrome were found in smoking $(p=0.004)$, hypertension $(p=0.047)$, tobacco use $(p=0.007)$, triglyceride $(p=0.014)$ and fasting blood glucose $(p=0.05)$.

Metabolic Syndrome with five, four and three components was documented in $2.5 \%, 35 \%$ and $62.5 \%$ patients respectively. Only 31 (25.8\%) patients with metabolic syndrome had diabetes mellitus, remaining 89 (74.2\%) were non diabetic. Significant difference $(\mathrm{p}<0.05)$ between these two groups (metabolic syndrome and nonmetabolic syndrome) were found in hypertension $(p<0.001)$, diabetes mellitus $(p=0.004)$, total cholesterol $(\mathrm{p}=0.043)$ and fasting glucose $(\mathrm{p}=0.001)$.

Conclusions: Metabolic syndrome is most common and important risk factor in patients of coronary artery disease. Other risk factors like smoking, obesity, dyslipidemia, hypertension and diabetes were also frequently found. Public awareness to control the risk factors can reduce the prevalence of coronary artery disease in our country.
\end{abstract}

Keywords: metabolic syndrome, acute coronary syndrome,

Correspondence:

Dr. Ajay Rajbhandari,

Consultant Physician,Shree Birendra Hospital

Chauuni, Kathmandu

Email: drajay9057@hotmail.com 


\section{INTRODUCTION}

The metabolic syndrome is one of the major public health issues of this century. It is a constellation of physical conditions and metabolic abnormalities, commonly occurring together. If the current trend continues, these conditions will increase the financial burden in developed and developing countries.

The prevalence of Metabolic Syndrome (MS) and cardiovascular disease (CVD) among South Asians is increasing. This trend is not only seen in South Asians residing on the Indian subcontinent (eg, India, Pakistan, Bangladesh, Nepal), but is also observed in countries with large numbers of South Asian immigrants ${ }^{1}$. It is estimated that $20 \%-25 \%$ of South Asians have developed MS and many more may be prone to it. Urbanization, economic growth, irregular timing of meals and dietary westernization has been suggested as potential culprits implicated in the development of this disorder ${ }^{2}$. In the year 2005, 58 million people died from CVD accounting for $30 \%$ of all deaths worldwide; more than half these deaths were in developing countries ${ }^{3}$. If the risk factors associated with CVD go unchecked, then by 2030 , when the world population is expected to reach 8.2 billion, 33 percent ( 24.2 million) of all deaths will be due to CVD ${ }^{4}$.

The aim of the present study was to determine the prevalence of Metabolic Syndrome (MS) using the National Cholesterol Education Program - Adult Treatment Panel III (NCEP-ATP III) criteria ${ }^{5}$ the frequency and combination of its definitive components in patients with Acute Coronary Syndrome (ACS) in Nepal.

\section{METHODS}

We performed a hospital-based cross sectional prospective study of consecutive patients admitted in Cardiac Care Unit with diagnosis of acute coronary syndrome at Bir Hospital and Shahid Ganga Lal Heart Center in Kathmandu, Nepal, from 16th July 2005 to 10th August 2006. Total 209 patients with coronary artery disease (Acute coronary syndrome) were enrolled. Patients having coronary by-pass surgery in past, age less than 18 years and other co-morbid diseases were excluded. All patients were informed about the study and a written consent was obtained from them. Acute coronary syndrome (ACS) was diagnosed on the basis of ECG changes and rises in cardiac enzymes and further classified into ST elevation Myocardial Infarction (STEMI), Non-ST elevation Myocardial Infarction (NSTEMI) and unstable angina.
Demographic data and presence of known risk factors like hypertension, diabetes mellitus, smoking and dyslipidemia were obtained, along with level of physical activity of at least $30 \mathrm{~min}$ daily or 5 days a week. Intake of any antihypertensive drugs, hypoglycemics and lipid lowering drugs were documented. Subjects were assessed for the five components of metabolic syndrome. Fasting blood samples were drawn for glucose and lipid profile in first 24 hours after acute coronary insult. Blood pressure was measured by using a standard mercury sphygmomanometer after the subject's pain and anxiety were relieved and the mean value of two measurements taken at least 15 minutes apart was used in the analysis.

Anthropometrics: Height was measured with a stadiometer to the nearest $\mathrm{cm}$; Weight was measured in light clothing without shoes. Waist circumference was measured at narrowest diameter between costal margins and iliac crest or after locating the upper hip bone and top of the right iliac crest, placing the measuring tape in horizontal plane around the abdomen at the level of iliac crest. The body mass index was calculated as the ratio between the weight and the square of the height, according to the international criteria.

Metabolic Syndrome Definition: We applied NCEPATP III criteria 5 to define Metabolic Syndrome (MS). Metabolic syndrome was defined by the presence of 3 or more out of 5 components:

1. Central (abdominal) Obesity \{Elevated Waist Circumference (WC) Male: $\geq 90 \mathrm{~cm} /$ Female: $\geq 80$ $\mathrm{cm}\}$;

2. High Triglyceride (TG) $\geq 150 \mathrm{mg} / \mathrm{dL}$ or on drugs for elevated TG;

3. Low HDL-(High density lipoprotein- Cholesterol) [ $\leq 40 \mathrm{mg} / \mathrm{dL}$ (male), $\leq 50 \mathrm{mg} / \mathrm{dL}$ (female)] Or on drugs for reduced HDL-C;

4. Elevate Fasting blood glucose (FBG) $\geq 100 \mathrm{mg} /$ $\mathrm{dL}$ or on drugs for high sugar;

5. Elevated blood pressure (Systolic blood pressure/ diastolic blood pressure $>130 \mathrm{mmHg} />85 \mathrm{~mm}$ $\mathrm{Hg}$ ) or on drugs for hypertension.

Statistical Analysis: The data was collected on a pre-designed proforma and variables were entered on SPSS version 19. Frequencies and percentages were computed for qualitative variables and variables compared by Chi square test. Mean and standard deviation were calculated for quantitative variables and mean were compared between two groups (metabolic syndrome and normal metabolic status) by 
MJSBH July-December 2013|Vol 12| Issue 2

using independent sample t-test. P-value of 0.05 was considered as significant.

\section{RESULTS}

The clinical demographic baseline characteristics of the study population are shown in Table 1. A total of 209 patients of ACS were studied with a mean age of $57.87 \pm 12.45$ years (range 27 to 88 years). Maximum number of patients, 88 (42.1\%), were seen in the age group $>61$ years. STEMI was diagnosed in $102(48.8 \%)$ persons, NSTEMI was present in 31 (14.8\%) while unstable angina was seen in $76(36.4 \%)$. Frequency of components of metabolic syndrome are shown in table $\mathbf{2}$, results show prevalence of high FBG and high TG were more.

Table 1: Demographic baseline characteristic of patients with acute coronary syndrome $(n=209)$

\begin{tabular}{|c|c|}
\hline VARIABLES & VALUES \\
\hline Ages & $57.87 \pm 12.45$ \\
\hline \multirow[t]{2}{*}{ Sex } & Male $142(67.9 \%)$ \\
\hline & \begin{tabular}{|ll} 
Female $67(32.1 \%)$ \\
\end{tabular} \\
\hline Diabetes & $40(19.1 \%)$ \\
\hline Hypertension & $74(35.4 \%)$ \\
\hline Smokers & $163(78.0 \%)$ \\
\hline Ex-smoker & $1(0.5 \%)$ \\
\hline Tobacco & $29(13.9 \%)$ \\
\hline Family H/O CAD & $24(11.5 \%)$ \\
\hline \multirow[t]{4}{*}{ Age groups } & $<40$ years \\
\hline & 41-50 years $50(23.9 \%)$ \\
\hline & $51-60$ years $55(26.3 \%)$ \\
\hline & $88(42.1 \%)$ \\
\hline \multirow{3}{*}{$\begin{array}{l}\text { Types Of } \\
\text { Myocardial Infraction }\end{array}$} & $102(48.8 \%)$ \\
\hline & $31(14.8 \%)$ \\
\hline & $76(36.4 \%)$ \\
\hline
\end{tabular}

\begin{tabular}{|l|l|}
\hline FBG $(\mathrm{mg} / \mathrm{dL})$ & $119.19 \pm 42.07$ \\
\hline TC $(\mathrm{mg} / \mathrm{dL})$ & $189.61 \pm 51.74$ \\
\hline HDL-C $(\mathrm{mg} / \mathrm{dL})$ & $50.03 \pm 19.53$ \\
\hline LDL-C $(\mathrm{mg} / \mathrm{dL})$ & $105.29 \pm 43.49$ \\
\hline TG $(\mathrm{mg} / \mathrm{dL})$ & $199.81 \pm 74.35$ \\
\hline BMI $2529.9(\mathrm{~kg} / \mathrm{m} 2)$ & $77(36.8 \%)$ \\
\hline BMI $>30(\mathrm{~kg} / \mathrm{m} 2)$ & $14(6.7 \%)$ \\
\hline Metabolic Syndrome & $120(57.4 \%)$ \\
\hline Physical Activity & $83(39.7 \%)$ \\
\hline
\end{tabular}

Table 2: Frequency of Components of Metabolic Syndrome (n-120)

\begin{tabular}{|l|l|}
\hline \multicolumn{1}{|c|}{ Component of MS } & No. (\%) \\
\hline 1. WAIST CIRCUMFERENCE & $49(62.8)$ \\
\hline a. Male $\geq 90 \mathrm{~cm}$ & $32(76.8)$ \\
\hline b. Female $\geq 80 \mathrm{~cm}$ & $98(81.7)$ \\
\hline $\begin{array}{l}\text { 2. TG }>150 \mathrm{mg} / \mathrm{dL} \text { or on drugs for } \\
\text { elevated TG }\end{array}$ & $31(39.7)$ \\
\hline 3. REDUCED HDL-C & $29(69.0)$ \\
\hline a. Male $<40 \mathrm{mg} / \mathrm{dL}$ & $69(57.5)$ \\
\hline \begin{tabular}{l} 
b. Female $<50 \mathrm{mg} / \mathrm{dL}$ \\
\hline 4. HYPERTENSION
\end{tabular} & $100(83.3)$ \\
\hline $\begin{array}{l}\text { 5. Elevated Fasting Blood Glucose }>100 \\
\text { mg/dl or on drugs for high sugar }\end{array}$ & \\
\hline
\end{tabular}

According to NCEP-ATP III criteria, descriptive statistics for the general characteristics of 209 participants (89 in non-MS group and 120 patients in MS group) are shown in Table 3. There is significant differences $(p<0.05)$ between these two groups were found in hypertension $57.5 \%(\mathrm{p}<0.001)$, triglycerides $219.79 \pm 73.84(\mathrm{p}<0.001)$, diabetes mellitus $25.8 \%$ $(\mathrm{p}=0.004)$, fasting blood glucose $129.55 \pm 43.69$ (p$0.001)$, total cholesterol $195.84 \pm 57.73(\mathrm{p}-0.043)$.

Table 3: Baseline characteristics of the patients with and without MS markers.

\begin{tabular}{|c|c|c|c|c|}
\hline S.N. & RISK FACTORS & $\begin{array}{c}\text { MS } \\
(\mathrm{N}=120)\end{array}$ & $\begin{array}{l}\text { NMS } \\
(\mathrm{N}=89)\end{array}$ & $\begin{array}{c}\mathbf{P} \\
\text { VALUE }\end{array}$ \\
\hline 1 & $\begin{array}{l}\text { Male/ } \\
\text { Female }\end{array}$ & $\begin{array}{l}78(65.0 \%) / \\
42(35.0 \%)\end{array}$ & $\begin{array}{l}65(73.0 \%) / \\
24(27.0 \%)\end{array}$ & 0.219 \\
\hline 2 & Smoking & $90(75.0 \%)$ & $73(82.0 \%)$ & 0.228 \\
\hline 3 & Hypertension & $69(57.5 \%)$ & $5(5.6 \%)$ & $<0.001 *$ \\
\hline 4 & Tobacco & $12(10 \%)$ & $17(19.1 \%)$ & 0.06 \\
\hline 5 & $\mathrm{DM}$ & $31(25.8 \%)$ & $9(10.1 \%)$ & $0.004 *$ \\
\hline 6 & CAD history & $13(10.8 \%)$ & $11(12.4 \%)$ & 0.734 \\
\hline
\end{tabular}


MJSBH July-December 2013|Vol 12| Issue 2

\begin{tabular}{|c|l|l|l|r|}
\hline 7 & Physicallyinactive & $73(60.8 \%)$ & $53(59.6 \%)$ & $\mathbf{0 . 8 5 2}$ \\
\hline 8 & SBP & $127.93 \pm 23.19$ & $122.83 \pm 23.16$ & $\mathbf{0 . 1 1 8}$ \\
\hline 9 & DBP & $82.79 \pm 12.27$ & $80.38 \pm 15.20$ & $\mathbf{0 . 2 0 6}$ \\
\hline 10 & TC $(\mathrm{mg} / \mathrm{dL})$ & $195.84 \pm 57.73$ & $181.21 \pm 41.16$ & $\mathbf{0 . 0 4 3}$ \\
\hline 11 & LDL-C $(\mathrm{mg} / \mathrm{dL})$ & $106.72 \pm 46.00$ & $103.36 \pm 40.04$ & $\mathbf{0 . 5 8 2}$ \\
\hline 12 & HDL-C $(\mathrm{mg} / \mathrm{dL})$ & $51.88 \pm 24.41$ & $47.54 \pm 16.47$ & $\mathbf{0 . 1 1 2}$ \\
\hline 13 & TG $(\mathrm{mg} / \mathrm{dL})$ & $219.78 \pm 73.84$ & $172.89 \pm 66.47$ & $<\mathbf{0 . 0 0 1}{ }^{*}$ \\
\hline 14 & WC $(\mathrm{cm})$ & $87.58 \pm 14.37$ & $83.66 \pm 14.03$ & $\mathbf{0 . 0 5 1}$ \\
\hline 15 & BMI $\left(\mathrm{kg} / \mathrm{m}^{2}\right)$ & $24.50 \pm 3.39$ & $24.20 \pm 4.58$ & $\mathbf{0 . 5 8 9}$ \\
\hline 16 & FBG $(\mathrm{mg} / \mathrm{dL})$ & $129.55 \pm 43.69$ & $105.21 \pm 35.48$ & $<\mathbf{0 . 0 0 1 *}$ \\
\hline
\end{tabular}

Figure 1 shows, Metabolic Syndrome with five, four and three components was documented in $2.5 \%, 35 \%$ and $62.5 \%$ patients respectively.

Table 4 shows out of 120 patients with MS, male and female were $78(65.0 \%)$ and $42(35 \%)$ respectively. significant difference $(p<0.05)$ between male with metabolic syndrome and female with metabolic syndrome were found in smoking $83.3 \%(\mathrm{p}=0.004)$, hypertension $(64.1 \%)(\mathrm{p}=0.047)$, tobacco use $15.14 \%$ $(\mathrm{p}=0.007)$, triglyceride $231.82 \pm 73.69(\mathrm{p}=0.014)$ and fasting blood glucose $135.27 \pm 48.22(\mathrm{p}=0.05)$.
Only $31(25.8 \%)$ patients with MS had diabetes mellitus, remaining $89(74.2 \%)$ were non diabetic. Chief complaints of MS patients were chest pain $(\mathrm{n}=111,92.5 \%)$ and chest discomfort $(\mathrm{n}=5,4.2 \%)$. Central chest pain $(43.8 \%)$ was most frequent by retrosternal chest pain $(42.9 \%)$ in the chest pain group (including chest pain as secondary complaints). Out of total chest pain (n-111) non radiating type was present in $74(61.7 \%)$ cases. CPK-MB was tested in $120 \mathrm{MS}$ and 89 NMS patients with average of $65.49 \pm 84.141$ and $88.66 \pm 91.99$ respectively.

Figure 1: Frequency of metabolic components

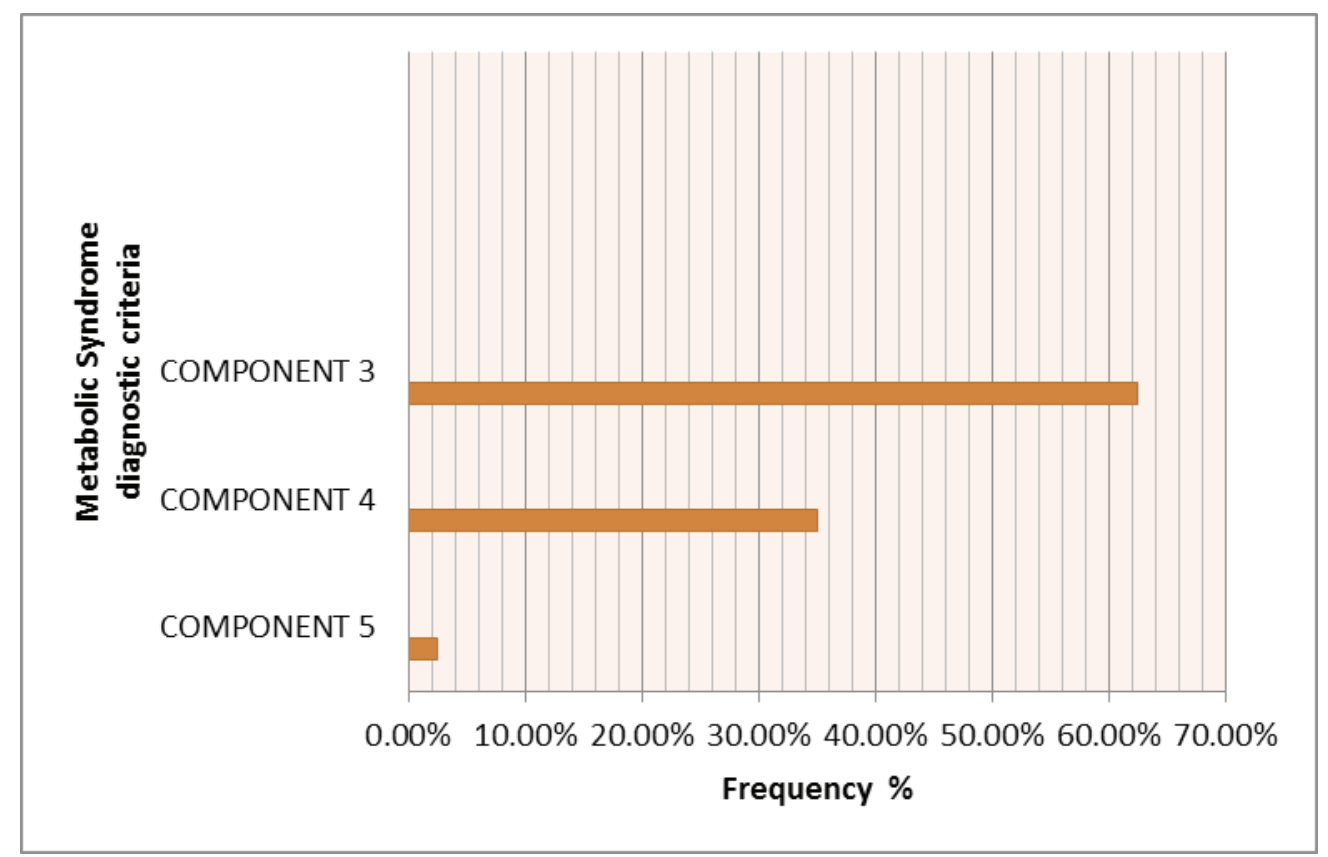

Table 4: Baseline characteristics of the patients with MS markers. ( n-120)

\begin{tabular}{|c|l|c|c|c|}
\hline S.N. & Risk factors & Male $(\mathrm{n}-78)$ & Female(n-42) & p-value \\
\hline 1 & Smoking & $65(83.3 \%)$ & $25(59.5 \%)$ & $0.004^{*}$ \\
\hline 2 & Hypertension & $50(64.1 \%)$ & $25(59.5 \%)$ & $0.047^{*}$ \\
\hline
\end{tabular}


MJSBH July-December 2013|Vol 12| Issue 2

\begin{tabular}{|c|l|c|c|c|}
\hline 3 & Tobacco & $12(15.4 \%)$ & $0(0.0 \%)$ & $0.007^{*}$ \\
\hline 4 & DM & $22(28.2 \%)$ & $9(21.4 \%)$ & 0.423 \\
\hline 5 & CAD history & $8(10.3 \%)$ & $5(11.9 \%)$ & 0.784 \\
\hline 6 & Physically inactive & $47(60.3 \%)$ & $26(61.9 \%)$ & 0.852 \\
\hline 7 & SBP & $130.18 \pm 19.67$ & $123.74 \pm 28.40$ & 0.147 \\
\hline 8 & DBP & $83.74 \pm 11.33$ & $81.02 \pm 13.82$ & 0.248 \\
\hline 9 & TC $(\mathrm{mg} / \mathrm{dL})$ & $203.18 \pm 60.99$ & $182.21 \pm 48.96$ & 0.057 \\
\hline 10 & LDL-C $(\mathrm{mg} / \mathrm{dL})$ & $108.41 \pm 46.62$ & $103.57 \pm 45.23$ & 0.585 \\
\hline 11 & HDL-C $(\mathrm{mg} / \mathrm{dL})$ & $52.49 \pm 22.53$ & $50.76 \pm 19.37$ & 0.676 \\
\hline 12 & TG $(\mathrm{mg} / \mathrm{dL})$ & $231.82 \pm 73.69$ & $197.40 \pm 69.54$ & $0.014 *$ \\
\hline 13 & WC $(\mathrm{cm})$ & $88.97 \pm 14.40$ & $84.98 \pm 14.12$ & 0.147 \\
\hline 14 & BMI $\left(\mathrm{kg} / \mathrm{m}^{2}\right)$ & $24.32 \pm 2.89$ & $24.82 \pm 4.19$ & 0.0 .442 \\
\hline 15 & FBG $(\mathrm{mg} / \mathrm{dL})$ & $135.27 \pm 48.22$ & $118.93 \pm 31.56$ & $0.050^{*}$ \\
\hline
\end{tabular}

\section{DISCUSSSION}

In our study the prevalence of MS in patients with ACS was higher using NCEP-ATP III, as was also observed in other studies ${ }^{6,7,8}$. These findings suggest that MS is very common among the patients with ACS. In this study, MS was detected more in male than that of female which is similar to Progetto CUORE study 9. The prevalence of MS was found more in age group $>61$ years in this study, as was observed similar in other studies ${ }^{10,11}$.

Our study, patients with ACS, confirmed the high prevalence of MS in patients with acute STEMI, which was same in study done in Korea ${ }^{12}$. According to the findings of the PROCAM study, in 40-65-year-old men with DM, there is an 8-fold risk of developing MI within 4 years in those with $\mathrm{DM}$ and $\mathrm{AH}$ and 19-fold risk in those with $\mathrm{DM}, \mathrm{AH}$, and dyslipidemia ${ }^{13}$.

According to the findings of our study three, four and five components were detected in $62.5 \%, 35 \%$, and $2.5 \%$ respectively. Literature quotes that more than one-half of patients with IHD and MS have three MS components, more than one-third of such patients have four MS components, and around 10-15\% - five MS components ${ }^{14,15,16}$.

In this study MS, regarding prevalence of sex, the results showed increased prevalence of MS in male than female but in many other studies showed predominately in female ${ }^{17,18}$. Risk factors like smoking, tobacco use, HTN, high TG and high FBG was found significantly high in male with MS as compared to female with MS. On the other hand, the men presented a greater frequency of smoking, an important cardiovascular risk factor that is not taken into account in the diagnosis of MS.

Regarding the prevalence of MS risk factors, in this study high FBG (83.3\%), high TG (81.7\%), HTN (57.5\%), high WC in female (76.2\%) and low HDL-C in female $(69.0 \%$ ), while in SEPHAR and NATPOL PLUS study AO, low HDL-C, and elevated blood glucose levels were less common ${ }^{19}$. Anderson et al. found that the most common components in patients with IHD were $\mathrm{AH}, \mathrm{AO}$, and low HDL-C, while elevated triglyceride concentration and DM were less common ${ }^{20}$; while in (SMART) study group, elevated blood pressure was the more prevalent risk factor about $(61 \%)^{17}$, while in Indian study ${ }^{18}$ and, in (CADISS) study ${ }^{21}$ low HDL was the most prevalent risk factor of MS.

\section{CONCLUSIONS}

Our study has identified the high prevalence of MS among patients with ACS and suggests that among MS components, hypertension, high FBG, high TG, diabetes mellitus has the strongest relationship with the increased incidence of CAD. Risk factors like smoking, tobacco use, high carbohydrate metabolism and hypertension found in high prevalence in male. The risk of cardiovascular events rises proportionally with the number of metabolic components.

\section{REFERENCES}

1. Yeolekar ME. Coronary artery disease in Asian Indians. J Postgrad Med. 1998;44(1):26-8. PMid:10703565

2. Misra A, Misra R, Wijesuriya M, Banerjee D. The 
metabolic syndrome in South Asians: continuing escalation and possible solutions. Indian J Med Res. 2007;125(3):345-54. PMid:17496360

3. Preventing chronic disease: a vital investment. Geneva, World Health Organization, 2005.

4. Mackay J, Mensah G: Atlas of Heart Disease and Stroke, Geneva, World Health Organization, 2004.

5. Executive Summary of the Third Report of the National Cholesterol Education Program (NCEP) Expert Panel on Detection, Evaluation, and Treatment of High Blood Cholesterol in Adults (Adult Treatment Panel III). JAMA 2001;285(19):2486-97. http://dx.doi.org/10.1001/ jama.285.19.2486

6. Chung E, Curran P, Sivasankaran. et al. Prevalence of metabolic syndrome in patients < 45 years of age with acute myocardial infarction having percutaneous coronary intervention. Am. J. Cardiol.,2007,100:1052-55. http:// dx.doi.org/10.1016/j.amjcard.2007.05.028. PMid:17884360

7. Zeller M., Steg PG., Ravisy J. et al. Prevalence of metabolic syndrome on hospital out comes in acute myocardial infarction. Arch. Intern. Med., 2005,165:1192-98. http://dx.doi.org/10.1001/ archinte.165.10.1192. PMid:15911735

8. Feinberg M., Schwartz A., Tanne D. et al. Impact of the metabolic syndrome on the clinical outcomes on non- clinically diagnosed diabetic patients with acute coronary syndrome. Am. J. Cardiol.,2007,99:667-72. http:// dx.doi.org/10.1016/j.amjcard.2006.10.023. PMid:17317369

9. Giampaoli S., Palmieri L., Donfrancesco C. et al. on behalf of Research Group of the Progetto CUORE. The metabolic syndrome: etiology, indentifying criteria, pathologic anatomy, utility for CVD risk prediction-data from the Progetto CUORE. Eur. Heart J. 2006, 27 (Suppl):852.

10. Pandey S., Baral N., Majhi P. et al. Prevalence of the metabolic syndrome in acute myocardial infarction and its impact on hospital outcomes. Int. J. Diab. Dev Ctries. 2009,vol 29(2):52-5.

11. Ford ES., Giles WH., Deitz WH. Prevalence of the metablic syndrome among US adults: Finding from Third National Health and Nutrition Examination Survey. JAMA. 2002;287:356-9. http://dx.doi.org/10.1001/jama.287.3.356.

12. Lee MG., Jeong MH., Ahn Y., et al. Impact of the Metabolic Syndrome on the Clinical Outcomes of Patients with Acute ST-Elevation Myocardial Infarction. J Korean Med Sci.2010;25:1456-61. http://dx.doi.org/10.3346/jkms.2010.25.10.1456. PMid:20890426 PMCid:PMC2946655

13. Assmann G, Schulte H. The Prospective Cardiovascular Münster (PROCAM) study: Prevalence of hyperlipidemia in persons with hypertension and/or diabetes mellitus and the relationship to coronary heart disease. Am Heart J 1988; 116(6):1713-24. http://dx.doi. org/10.1016/0002-8703(88)90220-7

14. Savage PD, Banzer JA, Balady GJ, Ades PA. Prevalence of metabolic syndrome in cardiac rehabilitation/secondary prevention programs. Am Heart J 2005;149:627-31. http://dx.doi. org/10.1016/j.ahj.2004.07.037. PMid:15990744

15. Bassand JP, Bauduceau B, Baleydier A, Ferlet JF, Paillasson S, Baigts F. Prevalence of atherothrombosis in patients with metabolic syndrome: insights from EXTRA registry including 7708 patients. Eur Heart J 2006;27(Suppl):384.

16. Ridker PM, Buring JE, Cook NR, Rifai N. $\mathrm{C}$-reactive protein, the metabolic syndrome, and risk of incident cardiovascular events. Circulation 2003;107:391-7. http://dx.doi.org/10.1161/01. CIR.0000055014.62083.05. PMid:12551861

17. Petra G, Jobien O, Yolanda G, et al. Prevalence of metabolic syndrome in patients with coronary heart disease, cerebrovascular disease, peripheral arterial disease or abdominal aortic aneurysm. Atherosclerosis 2004;173:363-9.

18. Ramachandran A, Sehalatha C, Satyavani K, et al. Metabolic syndrome in Asian Indian patients with ischemic heart diseases using ATP Ш criteria. Diabetes-Res-Clin-Practice 2003;60(3):199-204. http://dx.doi.org/10.1016/S0168-8227(03)000603.

19. Bandosz P, Dorobantu M, Zdrojewski T, Badila E, Darabont RO, Wyrzykowski B, et al. Prevalence of metabolic syndrome in Poland and Romania - data from 2 identical representative national surveys (SEPHAR and NATPOL PLUS). Eur Heart J 2006;27(Suppl):383.

20. Anderson JL, Horne BD, Jones HU, Reyna SP, 
Carlquist JF, Bair TI, et al. Intermountain Heart Collaborative (IHC) Study. Which features of the metabolic syndrome predict the prevalence and clinical outcomes of angiographic coronary artery disease? Cardiology 2004;101(4):185-93. http:// dx.doi.org/10.1159/000076695. PMid:14967961

21. Tawfik AH. Strategic approaches of the chronic diseases among GCC countries, Mediterranean conference on general medicine, 2006,p11. 